\title{
Comparison of feature based segmentation of full polarimetric SAR satellite sea ice images with manually drawn ice charts
}

\author{
M. -A. N. Moen ${ }^{1}$, A. P. Doulgeris ${ }^{1}$, S. N. Anfinsen ${ }^{1}$, A. H. H. Renner ${ }^{2}$, N. Hughes ${ }^{3}$, S. Gerland ${ }^{2}$, and T. Eltoft ${ }^{1,4}$ \\ ${ }^{1}$ Department of Physics and Technology, University of Troms $\varnothing, 9037$ Troms $\varnothing$, Norway \\ ${ }^{2}$ Norwegian Polar Institute, FRAM Centre, 9296 Troms $\varnothing$, Norway \\ ${ }^{3}$ Norwegian Ice Service, Norwegian Meteorological Institute, 9293 Troms $\varnothing$, Norway \\ ${ }^{4}$ Northern Research Institute, 9294 Troms $\varnothing$, Norway \\ Correspondence to: M.-A. N. Moen (mari-ann.moen@uit.no)
}

Received: 22 May 2013 - Published in The Cryosphere Discuss.: 13 June 2013

Revised: 19 September 2013 - Accepted: 28 September 2013 - Published: 7 November 2013

\begin{abstract}
In this paper we investigate the performance of an algorithm for automatic segmentation of full polarimetric, synthetic aperture radar (SAR) sea ice scenes. The algorithm uses statistical and polarimetric properties of the backscattered radar signals to segment the SAR image into a specified number of classes. This number was determined in advance from visual inspection of the SAR image and by available in situ measurements. The segmentation result was then compared to ice charts drawn by ice service analysts. The comparison revealed big discrepancies between the charts of the analysts, and between the manual and the automatic segmentations. In the succeeding analysis, the automatic segmentation chart was labeled into ice types by sea ice experts, and the SAR features used in the segmentation were interpreted in terms of physical sea ice properties. Utilizing polarimetric information in sea ice charting will increase the efficiency and exactness of the maps. The number of classes used in the segmentation has shown to be of significant importance. Thus, studies of automatic and robust estimation of the number of ice classes in SAR sea ice scenes will be highly relevant for future work.
\end{abstract}

\section{Introduction}

The Arctic sea ice cover has changed significantly during the last decades. The amount of multiyear ice has decreased and the general thinning of the ice cover supports the predictions that the Arctic will soon become dominated by first-year ice (Kwok et al., 2009; Maslanik et al., 2011). This development is a contributing factor to the observed increase in shipping and exploration activity in ice infested Arctic areas. Some human activities in polar areas are crucially dependent on precise and reliable sea ice maps. Such maps are also important for environmental monitoring and global climate change studies. Hence, studies of seasonal variations in sea ice properties and coverage have become increasingly important.

At present, synthetic aperture radar (SAR) is one of the most important remote sensors for monitoring and investigating sea ice, especially in the polar areas where the hostile climate and the remoteness limit the availability of in situ data (Clausi and Deng, 2004). A SAR imaging sensor, which operates in the microwave frequency band, provides all-weather and day-night high-resolution imagery. Recent radar sensors have polarimetric capabilities. A full-polarimetric SAR system transmits and receives both linear horizontal $(\mathrm{H})$ and vertical $(\mathrm{V})$ polarized electromagnetic waves, and hence provides measurements in four polarization channels (quad-pol). These are referred to as the $\mathrm{HH}, \mathrm{VV}, \mathrm{HV}$ and $\mathrm{VH}$ channels. The HH and VV channels are often referred to as the copolarization (co-pol) terms because the transmit and receive polarization is the same. The $\mathrm{HV}$ and $\mathrm{VH}$ terms are known as the cross-polarization (cross-pol) terms, as they relate to orthogonal polarization states. With full polarimetric capability, a SAR system is able to distinguish different scattering types, such as surface, volume and double-bounce scattering.

Quad-pol scenes can be acquired at very high resolution. The Radarsat- 2 scene analysed in this paper has a spatial resolution of $4.7 \mathrm{~m}$ (slant range) $\times 5.0 \mathrm{~m}$ (azimuth) and covers an area of $25 \mathrm{~km} \times 25 \mathrm{~km}$. Dual-pol scenes are images 
consisting of two polarimetric channels, such as $\mathrm{HH}$ and $\mathrm{HV}$ or VV and VH. These are preferred in operational ice charting services because of their much wider aerial coverage. Radarsat-2 ScanSAR Wide scenes have a coverage of $500 \mathrm{~km} \times 500 \mathrm{~km}$ with $160-72.1 \mathrm{~m}$ (ground range) $\times 100 \mathrm{~m}$ (azimuth) resolution.

Despite the currently very limited coverage, the detailed quad-pol images are crucial in order to understand the underlying physics of SAR imaging of sea ice. Investigation of full-polarimetric images will also contribute to an improved understanding of possibilities and limitations of single-pol and dual-pol images and helps select the optimal channel combinations.

The Canadian Ice Service (CIS) alone processes ten to twelve thousand SAR images every year (B. Duguay, personal communication, 2013). The Norwegian Ice Service manually produces ice concentration maps five days a week. The analysis of the large amount of satellite images is timeconsuming and pixel-level classification is not yet feasible. To our knowledge, there is no reliable automatic segmentation or classification algorithm that is operational at present (B. Duguay, personal communication, 2013, and F. Dinessen, personal communication, 2013). Hence, there is a need to improve automatic segmentation and classification approaches to ice charting and monitoring (Clausi and Deng, 2004; Ochilov and Clausi, 2010; Kwon et al., 2013; Zakhvatkina et al., 2013). However, the Norwegian Ice Service offers more frequently updated automatic ice concentration maps, but these maps are experimental (F. Dinessen, personal communication, 2013). For automatic products see: http://polarview.met.no/.

There is not much work published on the validation of manual ice classification charts or on pixel-to-pixel comparisons between manual charts and automatic segmentations utilizing SAR data exclusively. Due to lack of ground truth, manual ice charts are considered the best available sea ice information and thus often used for validation of automatic generated data sets (Clausi and Deng, 2004; Yu and Clausi, 2008; Ochilov and Clausi, 2010; Breivik et al., 2012; Kwon et al., 2013). Some information about validation of ice concentration maps is reported in Breivik et al. (2012).

Several techniques for automatic segmentation of SAR sea ice scenes exist. The approaches include thresholding of polarimetric features (Scheuchl et al., 2001; Dierking et al., 2003; Geldsetzer and Yackel, 2009), use of gamma distribution mixture models (Samadani, 1995), K-means clustering ((Hartigan, 1975; Karvonen, 2010), neural networks (Hara et al., 1995; Karvonen, 2004; Bogdanov et al., 2005; Zakhvatkina et al., 2013), Markov random field models (Deng and Clausi, 2005), Gaussian mixture models (Karvonen, 2004) and the Wishart classifier (Scheuchl et al., 2002, 2003). Gill and Yackel (2012) explored the classification potential of various SAR polarimetric parameters using supervised classifications. The iterative region growing using semantics (IRGS) method, which combines edge-based and region-growing-based segmentation methods, is generally considered the state-of-the-art approach (Yu and Clausi, 2008; Ochilov and Clausi, 2010; Clausi et al., 2010).

This paper focuses on sea ice type information retrieval from full-polarimetric SAR scenes. We examine both manually classified ice charts generated by sea ice experts, and automatic segmentation results obtained by an automatic algorithm. None of the charts were intended for operational use. In particular we seek answers to the following questions:

1. How well do manually generated and automatically generated segmentation maps match?

2. Can polarimetric parameters improve the separation between different ice types?

3. Can a physical interpretation of polarimetric features be exploited to label segments found by the automatic algorithm?

One of the polarimetric parameters utilized in the segmentation, the relative kurtosis (RK) (see Sect. 3.2), has not been used in sea ice classification previously.

In this study we present results from data acquired during a field cruise to the edge of the Arctic Basin, north of Svalbard, in April 2011.

This paper is organized as follows: Sect. 2 describes the data set, satellite data and in situ measurements analysed in this study. In Sect. 3 we explain how the manual and the automatic segmentation are produced and how the intercomparisons between them are performed. The analysis of the data and the findings are presented in Sect. 4. The results are discussed in Sect. 5 and conclusions are given in Sect. 6.

\section{Data}

\subsection{Satellite data}

The satellite images were acquired by Radarsat-2, which is the second Canadian C-band SAR satellite. The Radarsat-2 SAR payload offers high resolution $(3 \mathrm{~m})$ imaging and full flexibility in the selection of polarization channels, and is the first commercial space-borne SAR satellite to offer fullpolarimetric capabilities (Lee and Pottier, 2009). The satellite scenes from the campaign north of Svalbard in April 2011 contain first-year drifting sea ice at various stages of development and open and refrozen leads. This study focuses on a fine quad-pol scene acquired on 12 April 2011 at an incidence angle of $40^{\circ}$. The scene is located north of Svalbard (Fig. 1). A Pauli colour coded representation (Lee and Pottier, 2009) of the scene is shown in Fig. 2a. That is, the polarimetric intensity channel combinations $|\mathrm{HH}-\mathrm{VV}|$, $2|\mathrm{HV}|$ and $|\mathrm{HH}+\mathrm{VV}|$ are assigned to the RGB channels, respectively. Three major scattering mechanisms can be visually differentiated by inspecting a Pauli image. Singlebounce scattering, such as scattering from a surface appears 


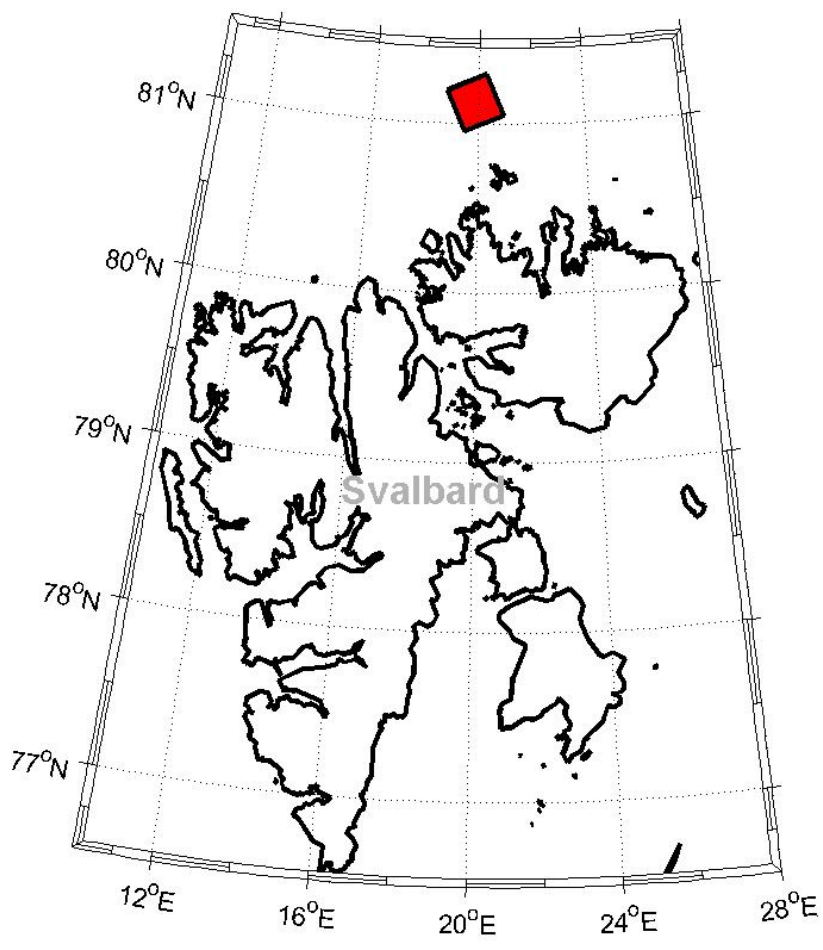

Fig. 1. Location of Radarsat-2 image, 12 April 2011. Red box north of Svalbard (center $81.1^{\circ} \mathrm{N} 19.1^{\circ} \mathrm{E}$ ).

bluish and the intensity depends on the roughness and orientation to the radar. That is, a smooth surface will reflect most of the power away from the radar sensor, unless it is directly oriented towards the sensor, while rougher surfaces have a significant diffuse backscatter at greater angles. Dihedral corners, like buildings or water/ice edges, causes double-bounce scattering which appears red/purple in the Pauli representation. The green colour represents depolarisation, often as a result of multiple random scattering from within the volume of the material. This type of scattering occurs in multiyear ice because its low salinity allows for penetration of the electromagnetic (EM) waves into the ice where internal air bubbles and brine inclusions give multiple random reflections of the signal.

The 12 April data set includes a broad collection of in situ data. The time lag between the satellite overpass and the start and end of a series of helicopterborne sea ice thickness measurements was $37 \mathrm{~min}$ and $1 \mathrm{~h}$ and $46 \mathrm{~min}$, respectively. The relatively short time span allows for an accurate sea ice drift correction.

\subsection{In situ measurements}

The collection of in situ measurements from 12 April 2011 comprises measurements of total thickness (snow plus ice thickness) retrieved during a helicopter flight, positions from different global positioning system (GPS) trackers, the bridge-based sea ice observation log, and optical images from the Norwegian Coast Guard Vessel (NoCGV) Svalbard. Ice thickness measurements were obtained from a helicopterborne EM induction sounder, called the "EM-bird", flown inside the area covered by the satellite image (see Fig. 2a). We include here a short introduction to sea ice thickness measurements using the EM-bird. More details can be found in Haas et al. (2009).

The large difference in conductivity between sea water and sea ice makes it possible to measure sea ice thickness by EM induction. The instrument induces an EM-field at the ice/water interface. The field strength and phase are used to calculate the distance between the instrument and the bottom of the sea ice. The distance from the EM-bird to the air-ice interface, or air/snow interface in the case of snow-covered sea ice, is provided by a laser altimeter mounted on the EMbird. The differences between these two measured distances is the total thickness within the footprint of the EM-bird ( 40-50 m) (Renner et al., 2013). The ice and snow thickness distribution derived from the EM-bird measurements on 12 April 2011 is shown in Fig. 3.

Optical images from a camera (GoPro, model YHDC5170) were also acquired during these flights. The camera was mounted on the helicopter's chassis, looking downwards onto the ice, and acquiring images at a frequency of $0.5 \mathrm{~Hz}$. An Iridium Surface Velocity Profiler (ISVP) buoy was deployed onto an ice floe on 11 April 2011. Every hour the buoy transmitted its position together with other parameters. The positions can be used to calculate the ice drift in the buoy's vicinity. A GPS transmitter (Garmin DC-40 collar) was placed on the ice to track the ice drift occurring between and during the EM-Bird flight and satellite image acquisition. The GPS receiver (Garmin Astro 220 with Astro portable long range antenna) onboard the ship received the collar positions every $30 \mathrm{~s}$ on average. The ice drift during the time span of $1 \mathrm{~h}$ and 46 min was significant. We chose to compute the average ice drift during the EM-bird flight based on the Garmin Astro GPS due to the higher frequency of GPS-positions. The displacement of each thickness measurement was calculated based on its time-lag to the satellite image acquisition time and the average drift velocity. Fig. 2a shows a Pauli image annotated with the original (red) and the corrected (white) helicopter track. The air temperature at the Radarsat-2 image acquisition time was $-19.6^{\circ} \mathrm{C}$ and the wind speed was $11.4 \mathrm{~m} \mathrm{~s}^{-1}$.

\section{Method}

In this section we present the methods used for the preparation of the manual ice charts and the automatic segmentation of the SAR data, all were non-operational ice charts. We also give a physical interpretation of the features used in the automatic algorithm. The last part of this section describes the 

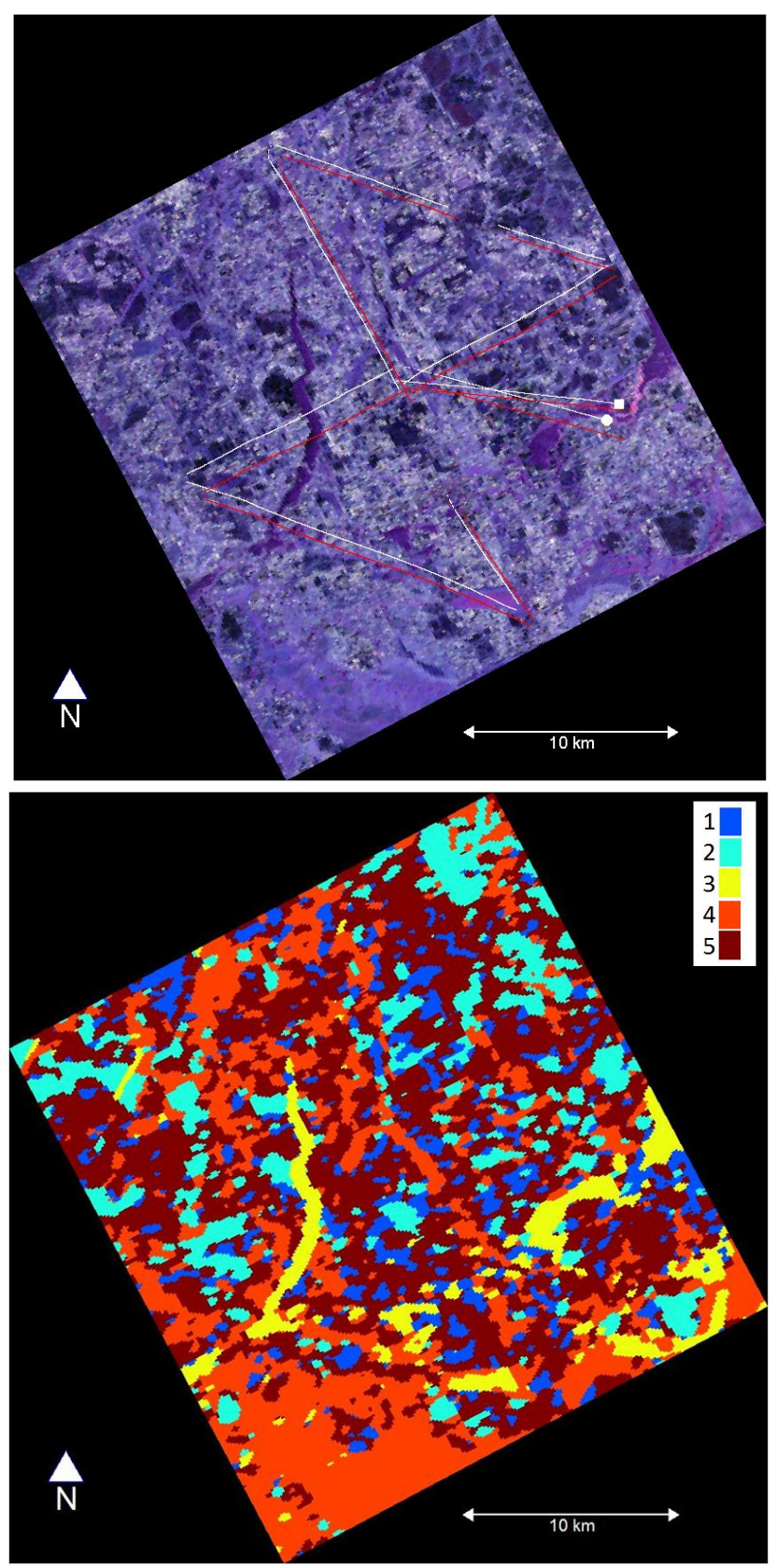

Fig. 2. Radarsat-2 scene, 12 April 2011. (a) Geocoded polarimetry image shown as Pauli colours (the intensity channel combinations $|\mathrm{HH}-\mathrm{VV}|, 2|\mathrm{HV}|$ and $|\mathrm{HH}+\mathrm{VV}|$ are assigned to the RGB channels, respectively). The original helicopter track is shown in red and the drift corrected track in white. The flight started at the white square and ended at the white circle. (b) Image segmented by the automated segmentation algorithm, with the number of classes set to five.

intercomparison of the hand-drawn ice maps and the automated segmentation.

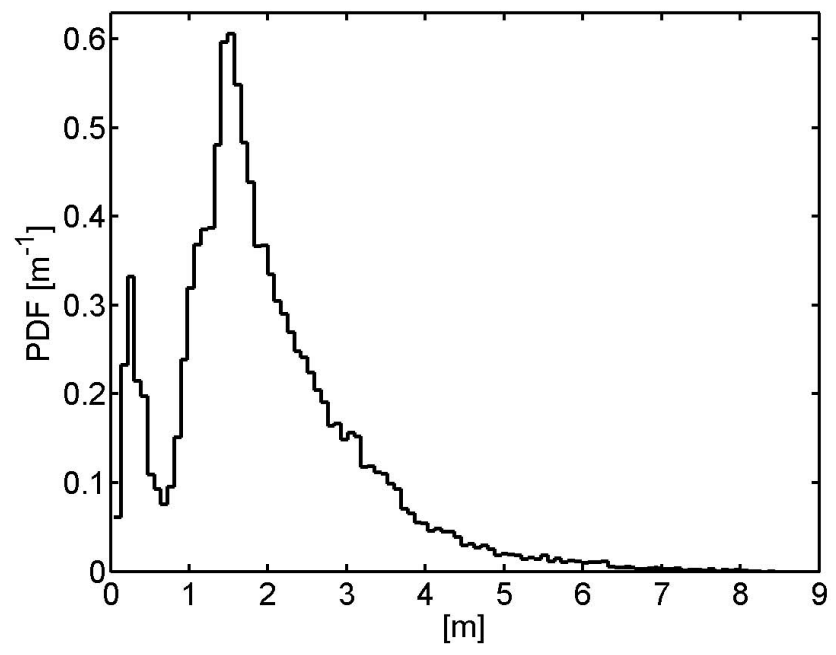

Fig. 3. Total thickness distribution from EM-Bird measurements 12 April 2011 along the flight track shown in Fig. 2.

\subsection{Manual segmentation and classification}

The 12 April quad-pol scene was manually and independently segmented and classified by two ice analysts at the Norwegian Ice Service. The analysts were instructed to concentrate on determining the ice stage of development $(\mathrm{SoD})$ and the ice type. The codes and colours used in the manual ice maps are those defined for standard World Meteorological Organization (WMO) stage of development ice charts (World Meteorological Organization, 1989) with the addition of a second class 2 for frost-flower-covered nilas. The authors would like to stress that the ice analysts have less experience in using quad-pol SAR scenes for ice type classification. The Norwegian Ice Service's operational ice charts are manually drawn based on dual-pol ScanSAR Wide data and available optical data. These charts are usually ice concentration maps, since the users are mainly interested in the ice edge and areas where it is possible to navigate into the ice. More information about operational manually drawn ice charts can be found in MANICE, (2005), 146 pp..

The scene was presented to the analysts as both radar backscatter coefficient $\sigma_{0}$ in a colour composite (RGB) constructed from the VV, HV and HH channels, and as a Pauli decomposition (Fig. 2a). The analysts were able to access the separate channels as grey-scale images by switching off channels. In addition, they were allowed to refer to the shipboard ice $\log$ and photographs from the NoCGV Svalbard. No other data was available for the following analysis. Areas observed by eye to be of similar appearance in the backscatter and Pauli image were masked out by using the geographic information system (GIS) software to manually draw polygons. Use of GIS permits an ice type attribute to be applied to each polygon. This is used to determine the colouring of the final ice map. 


\subsection{The automatic segmentation}

In this section we will explain how the features used in the automatic segmentation are extracted. Those readers who are not familiar with radar images may skip to section 3.3 without any contextual loss.

From a quad-pol SAR instrument, the complex scattering coefficients for all possible combinations of transmit and receive polarization are obtained. The scattering coefficients $S_{i j}, i, j \in\{\mathrm{H}, \mathrm{V}\}$ are subscripted with the associated receive and transmit polarisation. From the original scattering vector, $\boldsymbol{s}=\left[S_{\mathrm{HH}}, S_{\mathrm{HV}}, S_{\mathrm{VH}}, S_{\mathrm{VV}}\right]^{\mathrm{T}}$, we calculated the reduced scattering vector, $\boldsymbol{s}_{\mathrm{red}}=\left[S_{\mathrm{HH}}, \frac{1}{\sqrt{2}}\left(S_{\mathrm{HV}}+S_{\mathrm{VH}}\right), S_{\mathrm{VV}}\right]^{\mathrm{T}}$, by assuming reciprocity $\left(S_{\mathrm{HV}} \simeq S_{\mathrm{VH}}\right)$. The operator ()$^{\mathrm{T}}$ defines the ordinary transpose operation, and the factor $\frac{1}{\sqrt{2}}$ ensures that the averaged cross-pol term preserves the power contained in the individual original cross-pol terms. In the following the scattering vectors are the reduced three-dimensional vectors with dimension $d=3$.

The covariance matrix, given by Eq. (1), is calculated by averaging over $\mathrm{L}$ number of scattering vectors. This process needs to balance several conflicting requirements, e.g. speckle noise reduction, increase of radiometric distinction, degraded pixel resolution. In this study, $L=21 \times 21=441$, which is a reasonable compromise for this data set. The averaging is done by using a stepping window.

$\mathbf{C}=\frac{1}{L} \sum_{i=1}^{L} s_{i} s_{i}^{\mathrm{H}}$

where

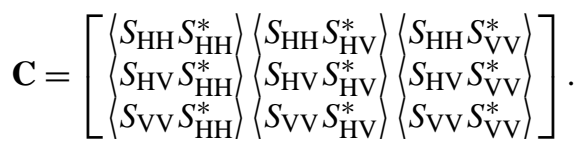

The operator ()$^{\mathrm{H}}$ defines the Hermitian transpose operation, and \langle\rangle is the sample mean over $L$ reduced scattering vectors in a local neighbourhood. The ground resolution, after averaging over 441 scattering vectors, is $103 \mathrm{~m}$ (azimuth) $\times 132 \mathrm{~m}$ (range). Six empirical real-valued features were extracted from the covariance matrix using the Extended Polarimetric Feature Space (EPFS) method (Doulgeris and Eltoft, 2010; Doulgeris, 2013). Five features are basic polarimetric parameters known to characterize the polarimetric signature of the illuminated area. This standard feature space has been extended to include a non-Gaussianity feature. All features have shown good potential in segmentation and most of them have a reasonable physical interpretation. More information can be found in Drinkwater et al. (1992) and Doulgeris (2013). The non-Gaussianity feature (Eq. 3) is computed using both the scattering vectors and the covariance matrix. The equations defining the features are given in Eqs. (3)-(8).

\section{Relative kurtosis}

$\mathrm{RK}=\frac{1}{L d(d+1)} \sum_{i=1}^{L}\left[\boldsymbol{s}_{i}^{\mathrm{H}} \mathbf{C}^{-1} \boldsymbol{s}_{i}\right]^{2}$.

The relative kurtosis (RK) is a statistical measure of the shape of the distribution. It is the absolute kurtosis measure divided by the absolute kurtosis of a Gaussian distribution, hence the name "relative" kurtosis. Normalizing by division falls naturally out of the product model, commonly used for radar texture modeling (Oliver and Quegan, 2004; Doulgeris, 2013). Distributions with high kurtosis are characterized by having a sharp peak close to the mean, a rapid decline and heavy tails relative to Gaussian data. Gaussian statistics occur when we have a large number of scatterers of similar strength. Large values of RK could indicate ice edges, rubble fields and deformations that create a few strong reflections and thus violate the Gaussian assumptions. Inhomogeneous areas will also produce enlarged RK values, due to intensity differences in the mixture components, even when the radar reflections are not particularly strong.

\section{Geometric brightness}

$B=\sqrt[d]{\operatorname{det}(\mathbf{C})}$.

The brightness feature $(B)$ represents the intensity of the multichannel radar backscatter. Here we have used the geometric mean brightness rather than the span, i.e. trace $(\mathbf{C})$. The $B$ is the geometric mean of all channels and is related to roughness, geometric shape and orientation with respect to the radar.

\section{Co-polarization ratio}

$R_{\mathrm{VV} / \mathrm{HH}}=\frac{\left\langle S_{\mathrm{VV}} S_{\mathrm{VV}}^{*}\right\rangle}{\left\langle S_{\mathrm{HH}} S_{\mathrm{HH}}^{*}\right\rangle}$.

The co-polarization ratio, $R_{\mathrm{VV} / \mathrm{HH}}$, has shown to be suitable for separating open water from thin-ice types (Scheuchl et al., 2001). Its value is determined by the dielectric constant of the surface. The largest ratio is observed for open water and new ice, while first-year and multiyear ice have values of $\sim 1$ (Onstott and Shuchman, 2004).

\section{Cross-polarization ratio}

$R_{\mathrm{HV} / B}=\frac{\left\langle S_{\mathrm{HV}} S_{\mathrm{HV}}^{*}\right\rangle}{B}$.

In Scheuchl et al. (2001), the HV channel was found to discriminate well between open water and ice. We have defined the cross-polarization ratio as the ratio of cross-pol intensity to geometric brightness. This ratio gives an estimate of the amount of depolarization, and is useful for discriminating ice type and estimating ice age. 


\section{Co-polarization correlation magnitude}

$|\rho|=\left|\frac{\left\langle S_{\mathrm{HH}} S_{\mathrm{VV}}^{*}\right\rangle}{\sqrt{\left\langle S_{\mathrm{HH}} S_{\mathrm{HH}}^{*}\right\rangle\left\langle S_{\mathrm{VV}} S_{\mathrm{VV}}^{*}\right\rangle}}\right|$.

The interpretation of the co-polarization correlation magnitude, $|\rho|$, in sea ice research is yet to be determined (Onstott and Shuchman, 2004), but Drinkwater et al. (1992) indicated that it relates to both salinity and incidence angle. A study by Gill and Yackel (2012) found $|\rho|$ to decrease with incidence angle and with deformation. It was largest for open water, followed by smooth first-year ice and decreasing with deformation.

\section{Co-polarization correlation angle}

$\angle \rho=\angle\left(\left|S_{\mathrm{HH}} S_{\mathrm{VV}}^{*}\right\rangle\right)$.

The co-polarization correlation angle, $L \rho$, has shown useful for classification, as a proxy in thickness estimation of thin ice types (i.e., $<\sim 0.3 \mathrm{~m}$ ) (Thomsen et al., 1998a, b), and also to separate open water from ice. Its value is determined by the water and ice dielectric constants, with the largest difference for new ice (Onstott and Shuchman, 2004).

The six features are transformed such that each had approximately symmetric and Gaussian-like probability density functions (pdfs). The features were transformed as follows: we used the reciprocal of the RK. The geometric brightness, the co-polarization ratio and the crosspolarization ratio were logarithmically transformed. The copolarization correlation magnitude and the co-polarization correlation angle were not transformed. The joint pdf for the feature vector was modeled with a multivariate Gaussian mixture (MGM) distribution. The Expectation Maximization (EM) algorithm was applied for maximum likelihood estimation of the parameters in the MGM model. The algorithm segments the satellite image into a predefined number of classes (Doulgeris and Eltoft, 2010; Doulgeris, 2013).

The number of ice classes in the literature varies from three (Kwok et al., 1992) to fourteen (Mundy and Barber, 2001), when open water is included as a class. We manually estimated five classes based on optical images, the Pauli image, the sea ice observation log and the segmentation results obtained with different number of classes. According to the sea ice observation log of 12 April 2011, five different ice types (Grease, Nilas, Pancake, Grey-White, First-Year) and open water were observed. From the optical images taken from the helicopter we were able to recognize three classes. Approximately four classes were separable in the Pauli image. Increasing the number of classes used in the segmentation gives a more detailed segmentation, but the physical interpretation of the classes becomes more challenging (Karvonen, 2004).

Before comparing the automatic segmentation to the manually classified images, the segmented image was postpro- cessed using a majority voting filter with window size 3 by 3 pixels, applied twice, to smooth the segments.

\subsection{Intercomparison of hand-drawn ice charts and automated segmentation}

All products were geocoded to enable a pixel-to-pixel comparison between both ice charts and the automatic segmentation. All pixels in the "Ice of Undefined SoD" class were excluded. The comparison was carried out by using a confusion matrix for each image pair (Tables 1a-1c). Each column in the confusion matrix represents one class in one chart, and each row represents one class in the other chart. All numbers in the confusion matrices are percentages of the total number of pixels in the chart, i.e. they sum up to 100 . By examining the entries in each confusion matrix we were able to state how each class in one chart relates to any of the classes in another chart.

\section{Analysis}

The analysis was carried out in two main steps. The first step included an intercomparison of the manual ice charts and the automatic segmentation. The second step was to validate and interpret the automatically segmented image by using available in situ data. The chart comparison was based on the smoothed, geocoded segmentation (Fig. 2b) and the two sea ice maps prepared by analyst 1 and analyst 2 (Fig. 4). In the manual ice charts each ice class/ice SoD is assigned a colour and a number. The legend is shown at the top of Fig. 4.

\subsection{Comparison of the two hand-drawn ice charts}

A preliminary visual inspection of the two hand-drawn maps (Fig. 4) revealed a disagreement both in segmentation (delineation of homogeneous regions) and classification (grouping and labeling of similar segments). Especially the labeling is very different. However, a more detailed analysis showed some similarities in the segmentation, e.g., the purple segment at the bottom corner and the vertical lead in the middle of the image. By taking the labels into consideration, we noticed that the yellow (class 7) and all the green labels (classes 8-11) describe various stages of first-year ice. The segments labeled first-year ice at different stages are the areas with the most differences. Separating especially the first-year ice classes based on visual interpretation of intensity SAR images only seems to be a very subjective part of manual ice charting. Merging all the first-year ice classes would make the ice charts more alike. Ice services that use SAR for their SoD ice chart products distinguish the different first-year ice types, but not without the help of additional data such as coastal and shipboard ice observations and knowledge of the ice development history. Such additional data are not always available, which is why the code "First-Year" (code 6) is sometimes used. This code does not specify a sub-range of 


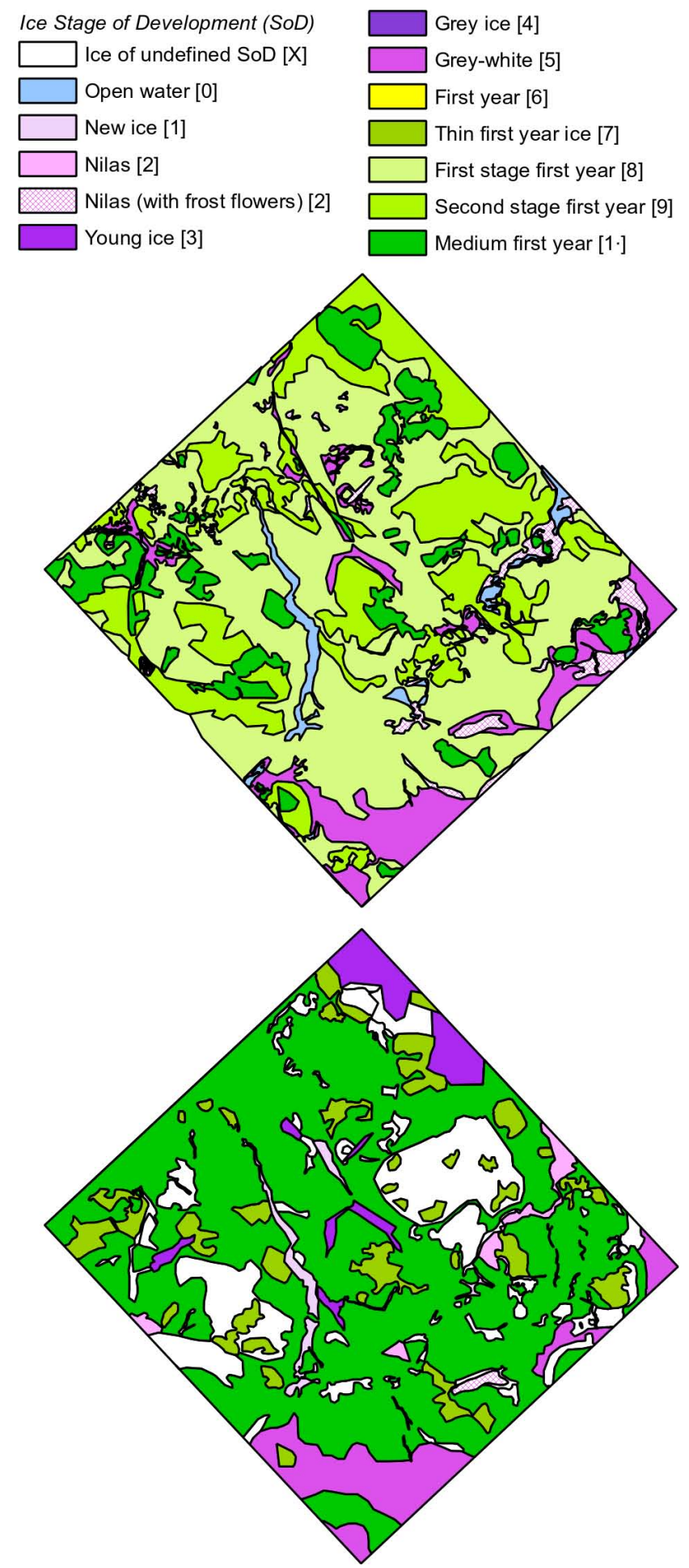

Fig. 4. Manual ice charts produced by analyst 1 (top) and analyst 2 (bottom). The legend with class labels and numbers is given at the top.

thicknesses within the definition of first-year ice, as opposed to codes $7,8,9,1 \cdot$ and 4 .
The confusion matrix from the comparison of the two hand-drawn ice charts is provided in Table 1a. All numbers are given as percentages of the total number of pixels in the image. Important numbers to be discussed in the following are written in boldface. The analysts label $9.3 \%$ and $7.7 \%$ of the pixels as Grey-White (code 5). This labeling is consistent for $6.1 \%$ of the pixels, which is approximately a oneto-one correspondence. We would also like to highlight that the biggest classes, First stage first-year (FSFY) (code 8) in analyst 1's chart and Medium first-year (MFY) (code 1.) in analyst 2's ice chart, correspond very well. They are consistent for $53.2 \%$ of the pixels. It is also worth noting that all $\left(100 \%=\frac{0.3 \%}{0.3 \%}\right)$ pixels in analyst 2 's class Nilas with frost flowers (code 2) are classified as the same class by analyst 1. However, the opposite is not true, analyst 1's class Nilas with frost flowers (code 2) is spread over several of analyst 2's classes.

\subsection{Comparison of hand-drawn ice charts and the automatic segmentation}

The intention of this section is to make a quantitative analysis of the relationships between the ice maps. The confusion matrix from the comparison between analyst 1's ice chart and the automatic segmentation is shown in Table $1 \mathrm{~b}$. Again, note that all percentages are relative to the total number of pixels in the image and important numbers to be discussed are written in boldface. A majority of the pixels in class $1\left(60.4 \%=\frac{6.4 \%}{10.6 \%}\right)$, class $4\left(53.5 \%=\frac{14.5 \%}{27.1 \%}\right)$ and class $5\left(63.8 \%=\frac{27.3 \%}{42.8 \%}\right)$ of the automatic segmentation are mapped into the dominant FSFY class (code 8) of the handdrawn ice chart. This many-to-one mapping is also seen for the Second stage first-year (SSFY) class (code 9). Analyst 1's SSFY class (code 9) is dispersed into all the classes of the automatic segmentation. However, the many-to-one mapping also applies in the other direction, e.g. $87.7 \%$ (= $\frac{6.4 \%+2.9 \%}{10.6 \%}$ ) of class 1 in the automatic segmentation and $97.3 \%\left(=\frac{27.3 \%+12.1 \%}{42.8 \%}\right)$ of class 5 in the automatic segmentation is distributed between analyst 1's FSFY (code 8) and SSFY (code 9) classes. This indicates an inconsistency between the manual classification and the automated segmentation.

Table 1c shows the confusion matrix made from the comparison of analyst 2's ice chart and the automatic segmentation. Important numbers to be discussed are written in boldface. This comparison also shows a many-toone mapping similar to the previous comparison. Now it is class $1\left(88.0 \%=\frac{9.5 \%}{10.8 \%}\right)$, class $4\left(67.0 \%=\frac{18.8 \%}{28.2 \%}\right)$ and class $5\left(91.4 \%=\frac{39.2}{42.9}\right)$ in the automatic segmentation that are mapped into the dominating MFY class (code 1.). As previously discussed, this class is known to correspond to the FSFY class of analyst 1 . The Young ice (code 3 ) is also an example of a many-to-one mapping. This class is scattered into class 2,4 and 5 of the automatic segmentation. However, 
Table 1a. Confusion matrix for hand-drawn ice charts (Fig. 4). SoD is the ice stage of development defined by WMO. 2(FF) indicates class 2 with frost flowers. Numbers are given in \%. Important numbers are written in boldface in Tables $1 \mathrm{a}-\mathrm{c}$.

\begin{tabular}{|c|c|c|c|c|c|c|c|c|}
\hline \multicolumn{9}{|c|}{ Analyst 1} \\
\hline & SoD & 0 & $2(\mathrm{FF})$ & 5 & 8 & 9 & 1 . & $\sum$ \\
\hline \multirow{8}{*}{$\frac{N}{\stackrel{N}{\pi}}$} & 1 & 1.1 & 0.0 & 0.1 & 0.3 & 0.2 & 0.1 & 1.8 \\
\hline & 2 & 0.8 & 0.5 & 0.0 & 0.1 & 0.2 & 0.0 & 1.6 \\
\hline & $2(\mathrm{FF})$ & 0.0 & 0.3 & 0.0 & 0.0 & 0.0 & 0.0 & 0.3 \\
\hline & 3 & 0.0 & 0.1 & 0.5 & 0.5 & 3.2 & 0.6 & 4.9 \\
\hline & 5 & 0.0 & 0.1 & 6.1 & 0.7 & 0.8 & 0.1 & 7.7 \\
\hline & 7 & 0.1 & 0.2 & 0.4 & 1.0 & 2.2 & 7.4 & 11.2 \\
\hline & $1 \cdot$ & 0.4 & 1.8 & 2.3 & 53.2 & 12.5 & 2.2 & 72.5 \\
\hline & $\sum$ & 2.5 & 3.1 & 9.3 & 55.7 & 19.0 & 10.4 & 100 \\
\hline
\end{tabular}

Table 1b. Confusion matrix for automated segmentation (Fig. 2b) and analyst 1's ice chart (Fig. 4). SoD is the ice stage of development defined by WMO. 2(FF) indicates class 2 with frost flowers. AS-class is the unlabeled segments from the automated segmentation. Numbers are given in $\%$.

\begin{tabular}{|c|c|c|c|c|c|c|c|}
\hline \multicolumn{8}{|c|}{ Automated segmentation } \\
\hline & \begin{tabular}{l} 
SoD \} $\\
{\text { AS-class }}$ & 1 & 2 & 3 & 4 & 5 & $\sum$ \\
\hline \multirow{7}{*}{ 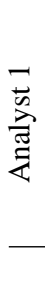 } & 0 & 0.1 & 0.0 & 2.0 & 0.1 & 0.1 & 2.3 \\
\hline & $2(\mathrm{FF})$ & 0.4 & 0.3 & 1.8 & 0.7 & 0.4 & 3.6 \\
\hline & 5 & 0.4 & 0.4 & 0.6 & 6.8 & 0.7 & 8.9 \\
\hline & 8 & 6.4 & 1.4 & 1.3 & 14.5 & 27.3 & 51.0 \\
\hline & 9 & 2.9 & 3.9 & 0.4 & 4.3 & 12.1 & 23.4 \\
\hline & 1 . & 0.5 & 7.2 & 0.1 & 0.8 & 2.3 & 10.8 \\
\hline & $\sum$ & 10.6 & 13.2 & 6.3 & 27.1 & 42.8 & 100 \\
\hline
\end{tabular}
\end{tabular}

the many-to-one mapping applies in both directions. For example $97 \%\left(=\frac{1.5 \%+7.7 \%+2.4 \%}{12.0 \%}\right)$ of class 2 , in the automatic segmentation, is distributed between the Young (code 3), the Thin first-year (code 7) and the MFY (code 1.) ice. Once again we conclude that the manual classification and the automatic segmentation are inconsistent.

\subsection{Validation and interpretation of the automatic segmentation}

From the visual inspections and confusion matrices we established that the manual classifications and the automatic segmentation are inconsistent. The question that arises is: which one of the maps is closest to the true physical ice types? The manually segmented ice charts are indisputably very subjective. They rely on the ice analyst's experience, but also on the available amount of data, including satellite scenes and in situ measurements.

On the other hand, the segments of the automatic segmentation must be labeled. An attempt at this was carried out by
Table 1c. Confusion matrix for automated segmentation and analyst 2's ice chart. SoD is the ice stage of development defined by WMO. 2(FF) indicates class 2 with frost flowers. AS-class is the unlabeled segments from the automated segmentation. Numbers are given in $\%$.

\begin{tabular}{|c|c|c|c|c|c|c|c|}
\hline \multicolumn{8}{|c|}{ Automated segmentation } \\
\hline & \begin{tabular}{l} 
SoD \} $\\
{\text { AS-class }}$ & 1 & 2 & 3 & 4 & 5 & $\sum$ \\
\hline \multirow{8}{*}{$\frac{N}{\tilde{\omega}}$} & 1 & 0.2 & 0.1 & 1.3 & 0.1 & 0.2 & 1.8 \\
\hline & 2 & 0.1 & 0.2 & 1.3 & 0.0 & 0.0 & 1.6 \\
\hline & $2(\mathrm{FF})$ & 0.0 & 0.0 & 0.3 & 0.0 & 0.0 & 0.3 \\
\hline & 3 & 0.3 & 1.5 & 0.0 & 1.8 & 1.3 & 4.9 \\
\hline & 5 & 0.1 & 0.1 & 0.3 & 7.0 & 0.3 & 7.7 \\
\hline & 7 & 0.7 & 7.7 & 0.3 & 0.5 & 2.0 & 11.1 \\
\hline & 1 . & 9.5 & 2.4 & 2.6 & 18.8 & 39.2 & 72.5 \\
\hline & $\sum$ & 10.8 & 12.0 & 6.1 & 28.2 & 42.9 & 100 \\
\hline
\end{tabular}
\end{tabular}

presenting sea ice experts from the Norwegian Polar Institute with available data (i.e., optical photos, thickness data with the corresponding segments from the automatic segmentation (Fig. 5a), the Pauli image (Fig. 2a) and the unlabeled ice chart (Fig. 2b). The class descriptions they delivered are shown in Table 2. The yellow segments are various types of thin ice and open water, the red segments are young ice, occasionally deformed and/or with snow cover. Examples of optical photos taken from the helicopter from the open water/thin ice (yellow) class are provided in Fig. 6. By examining the optical photos alone, the sea ice experts were not able to distinguish the blue, brown and the light blue segments. These were all first-year ice, but could probably be characterized by their different degree of deformation. However, by including the Pauli image, they were able to separate the light blue segments from the other classes. The light blue class appears dark in the Pauli image, and is therefore interpreted as smoother than the brown and blue class. This is to some degree supported by a visual inspection of Fig. 5a.

Ice thickness histograms for each class based on the EMbird thickness measurements were utilized to examine the thickness-based class discrimination (Fig. 5b). The dominant ice thickness of each segment is denoted by the main peak within each segment. However, the thickness histograms indicate mixed classes. This can occur as a result of coarse class boundaries and a co-location error of the EM-bird measurements and the satellite image. The latter is due to uncertainties in the drift correction. We trimmed each class region to avoid potentially contaminated thickness measurements close to the class boundaries.

The yellow class is very distinct from the other classes because of the large amount of open water/very thin ice and no ice thicker than $5 \mathrm{~m}$ (Fig. 5b). Before the trimming, the blue, light blue and brown classes are similar, which can explain the ice expert's difficulties to separate them. In the blue class, 

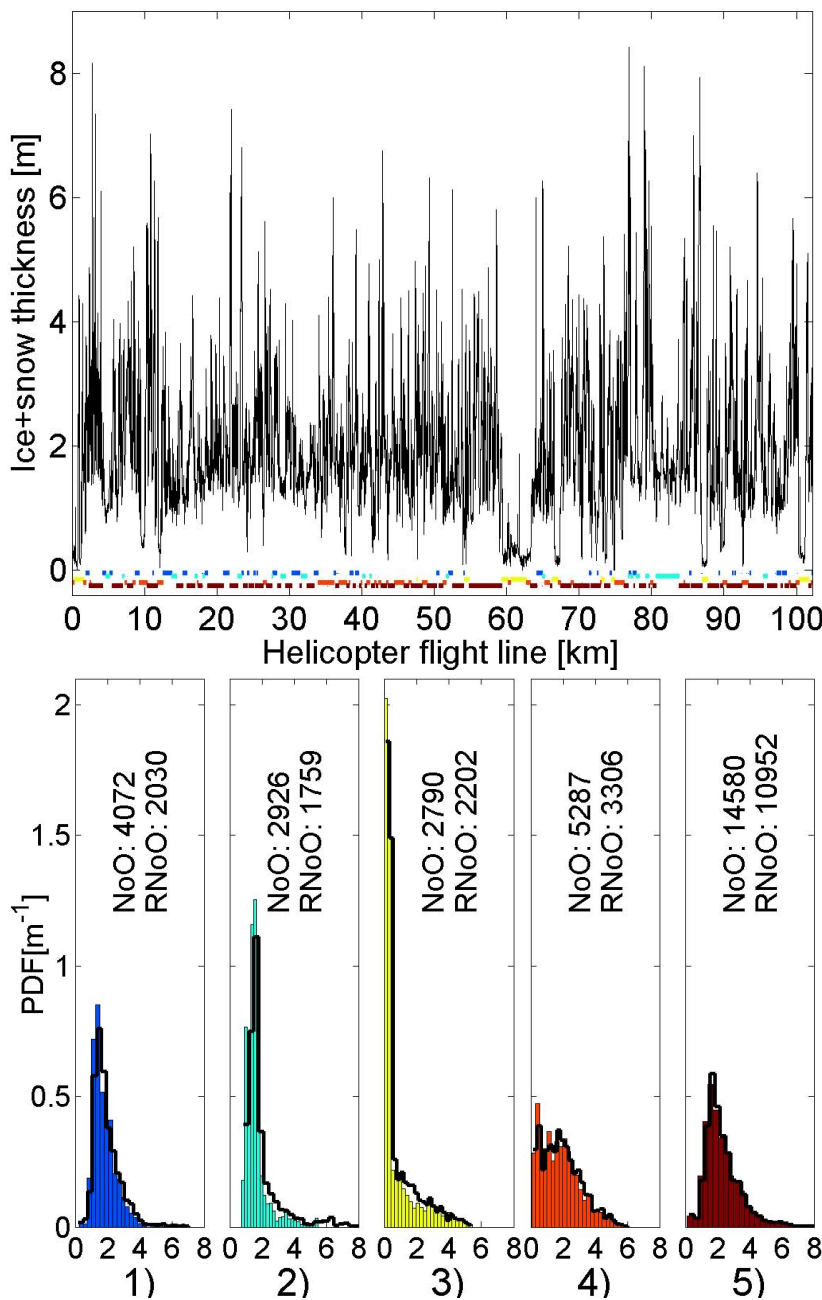

Fig. 5. EM-bird measurements of total thickness. Colours correspond to the classes from the automatic segmentation (Fig. 2b). The corresponding class labels can be found in Table 2. (a) EMbird thickness measurements with corresponding segments. High thickness values represent ridges (tail in pdf in Fig. 3). (b) Thickness PDFs from the EM-bird measurements for each class. NoO and $\mathrm{RNoO}$ is the number of observations and reduced number of observations after trimming, respectively. The bar histograms are based on the $\mathrm{RNoO}$ for each class, while the black line shows the distribution for the total NoO for each class. (1) is the blue class, (2) is the light blue class, (3) is the yellow class, (4) is the red class and (5) is the brown class. The $x$ axis is the ice plus snow thickness $[m]$ and the $y$ axis is the pdf.

the fraction of ice thicker than $4 \mathrm{~m}$ is lower than for the other two. The blue and the brown have very similar shape in the tail of the histograms, whereas the light blue seems to have more deformed ice with thickness larger than $4 \mathrm{~m}$. However, the modal peak of the light blue class is much sharper. This supports the interpretation of this class being smooth ice.

To further investigate the class discrimination we exploited physical information in the polarimetric features used in the segmentation algorithm. Our main attention was to examine

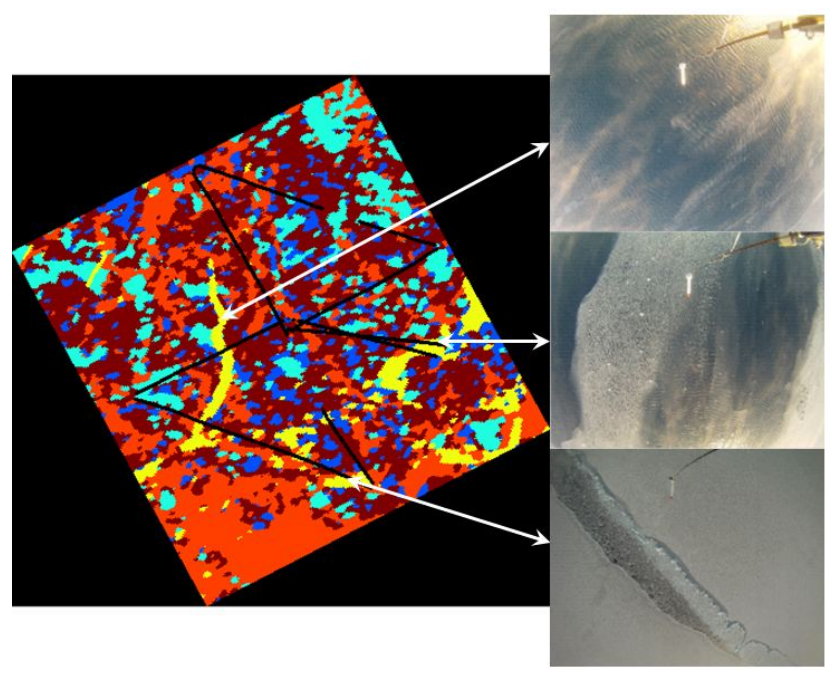

Fig. 6. Automatic segmented image (Fig. 2b), with example photos from the yellow class (thin ice/open water). The corresponding class labels can be found in Table 2. Helicopter track shown in black.

Table 2. Class labels produced by sea ice experts. The colours refer to those in automatic segmentation (Fig. 2b) and are the same in Figs. 5-8.

\begin{tabular}{ll}
\hline $\begin{array}{l}\text { Segment colour } \\
\text { (class number) }\end{array}$ & Stage of Development (SoD) \\
\hline Blue(1)/Light Blue(2)/ & First-year ice, \\
Brown(5) & different stages of development \\
Yellow(3) & Thin ice, \\
& open water, \\
& new ice, \\
& nilas, \\
& grey ice \\
& Young ice, thin first-year ice \\
& (sometimes deformed with snow cover) \\
\end{tabular}

the possibility to discriminate the three classes (blue, brown and light blue) that the ice experts were unable to separate. We expected the automatic segmentation to be influenced by outliers. For each of the six features we chose to calculate the median and the median absolute deviation about the median (MADAM). These two robust statistics are not unduly affected by outliers. Given the data set $X=X_{1}, X_{2}, \ldots, X_{N}$, the MADAM value is given by

$\operatorname{MADAM}=\operatorname{median}\left(\left|X_{i}-\operatorname{median}(X)\right|\right)$.

The results are shown in Fig. 7. The probability density functions (PDFs) for each class and each feature are shown in Fig. 8. All six features, and especially the co-pol ratio (Fig. 7d), separate the open water/thin ice (yellow) class very well. The co-pol ratio is sensitive to the dielectric constants of the water and ice, thus it is expected to discriminate the water and ice. The brightness feature is responsive 

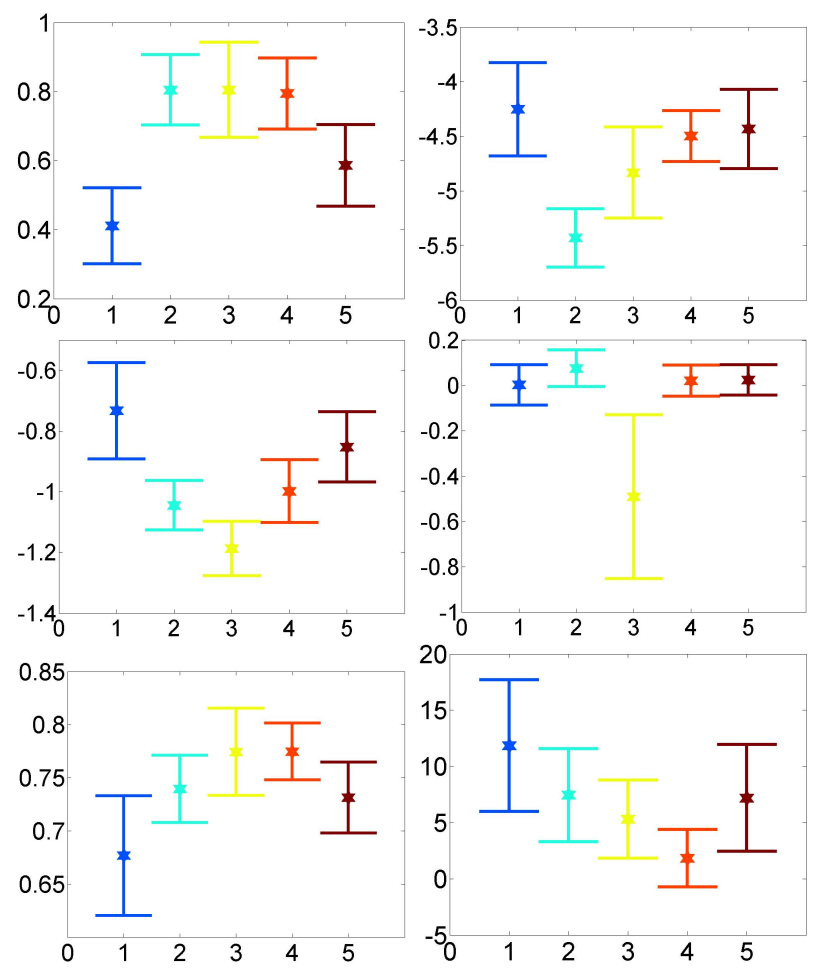

Fig. 7. Median for each class and each feature, the relative kurtosis (a), the brightness (b), the cross-pol ratio (c), the co-pol ratio (d), the co-pol correlation magnitude (e) and the co-pol correlation angle (f). The error bars are two MADAMs long (see Eq. 9), the $x$ axis corresponds to the class number and the $y$ axis is the median value.

to roughness. The blue class is the brightest, and thus we interpret it to be the most deformed ice type, the light blue class is the darkest one, and thus interpreted as smooth ice. This is in agreement with the light blue class being dark in the Pauli image. The cross-pol ratio is known to increase with deformation. Of the three classes we consider, Figs. 7c and $8 \mathrm{c}$ imply that the blue class is the most deformed and the light blue is the least deformed. This is consistent with the findings from the brightness feature and visual inspection of the Pauli image. The results from the inverse RK feature is shown in Fig. 7a. This feature is expected to be sensitive to deformation and inhomogeneous surfaces. The blue, brown and light blue classes appear to be well separated. Of these three, the blue class has the lowest values, indicating that it contains the most deformed ice. The light blue has the highest values and is interpreted as smooth ice. All this is in accordance with the findings stated above. We notice that the yellow class (open water/thin ice) is more Gaussian than the blue, deformed ice class. This separation is also visible in the co-pol correlation angle and magnitude plots (Figs. 7e-f and $8 \mathrm{e}-\mathrm{f}$ ).
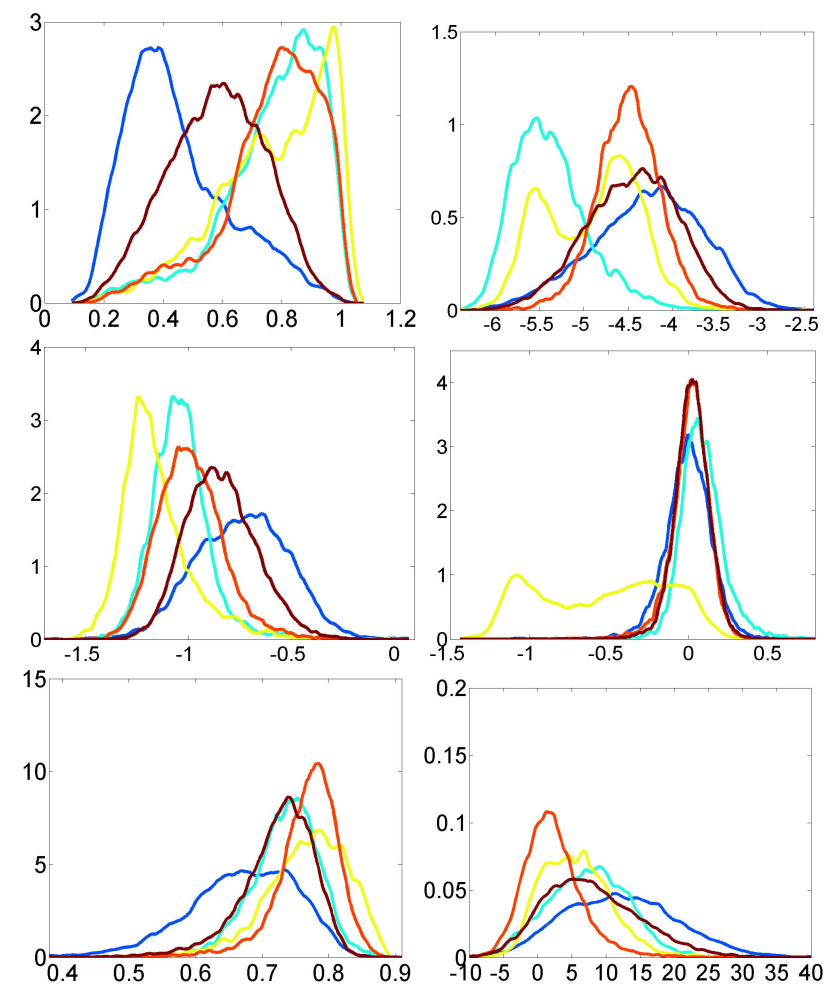

Fig. 8. Probability density functions (PDFs) for each class for the relative kurtosis (a), the brightness (b), the cross-pol ratio (c), the co-pol ratio (d), the co-pol correlation magnitude (e) and the co-pol correlation angle (f).

\section{Discussion}

\section{Comparison of ice charts}

The charts were not expected to be identical on a pixel level, due to the human factor in manual segmentation. Our investigation has shown though that all the charts are inconsistent. This inconsistency may occur for several reasons:

- The number of classes disagree in all ice charts. We believe that the main reason for the dissimilarity between the manual segmentations is the various labels of first-year ice. In other words, subjectivity appears to be an important factor in labeling the first-year ice in particular. The manual charts would probably be more similar if the number of first-year ice labels were reduced.

- The hand-drawn polygons have rough boundaries and poor detail, which could be a reason for the manyto-one mapping. More essentially, we believe the automated algorithm interprets the image information more rigorously, thus distinguishing more segments. 
- The segmentation may fail over some complex parts of the scene where the ice is heterogeneous and the detail level is high.

- The education and experience of the ice analysts may be one reason why the manually drawn charts differ. One of the analysts have sixteen years of experience drawing ice charts and the other one just two. They have little or no experience in thickness classification based on quad-pol images.

\section{Class labeling}

The class labeling was assisted by the EM-bird measurements and in that respect we need to address some limitations. First, the EM-bird averages the total thickness (snow plus ice) across its footprint, i.e., measurements taken above ice type borders or at ice/water boundaries are not representative for one specific class. Secondly, the EM-bird is not solely measuring the ice thickness. The measurements comprise the total snow and ice thickness. Optical images aid the interpretation of the segments, but the snow cover hampers the class labeling. Thus, distinguishing ice types based on thickness measurements (Fig. 5b) is not a trivial task. We see that the trimmed data set has lighter tails than the original data set, for some of the classes. The effect is most visible for the smooth ice (class 2) and the open water/thin ice (class 3). This indicates that the results are affected by (1) imperfect co-location of the EM-bird measurements and the polSAR measurements, (2) blurring effects within the EM-bird footprint.

\section{Polarimetric parameters}

In order to compare our polarimetric parameters to values reported by others, we calculated the mean value and standard deviation (Table 3). In the subsequent discussion the co-pol ratio is given in $\mathrm{dB}$. We found the mean co-pol ratio, $\overline{\mathbf{R}}_{\mathrm{VV} / \mathrm{HH}}$, to be largest and have the largest variability for open water/thin ice (class 2), which is in agreement with the findings of Geldsetzer and Yackel (2009). The other classes were close to zero. By re-defining the co-pol ratio as $\overline{\mathbf{R}}_{\mathrm{HH} / \mathrm{VV}}$, we found it to be positive for all ice types except for open water/thin ice, which is in accordance with the findings of Gill and Yackel (2012) and Drinkwater et al. (1992). Scheuchl et al. (2001) also reported negative co-pol values for open water. Gill and Yackel (2012) reported the co-pol ratio to increase with incidence angle for all positive values and decrease for open water. The incidence angle of our scene is less than the one in Drinkwater et al. (1992) and exceeds those used in Gill and Yackel (2012). We see that our co-pol ratio for open water/thin ice follows the trend and extrapolate those values found by Gill and Yackel (2012) and Drinkwater et al. (1992).

Our co-pol correlation magnitude varies between 0.67 and 0.77 , which corresponds well with the value
Drinkwater et al. (1992) reports for first-year ice at an incidence angle of $40^{\circ}$. The co-pol correlation magnitude is inversely related to the incidence angle (Drinkwater et al., 1992), which supports that all our co-pol correlation magnitudes are less than those reported by Gill and Yackel (2012). However, they reported the co-pol correlation magnitude of open water to be the greatest. In our study two classes, open water/thin ice (class 3 ) and young ice (class 4) had equally large co-pol correlation magnitude.

We found the mean co-pol correlation angle to be positive for all ice types. This does not coincide with the work of Gill and Yackel (2012), which reports negative angles for all ice types and open water. However, our findings correspond well with what was reported by Dierking et al. (2003), with one exception. They found that open water had negative phase differences. We found that the most deformed ice (class 1) had the largest value. The young ice (class 4 ) had the smallest mean angle. Gill and Yackel (2012) reported negative mean phase differences at all incidence angles and for all ice types.

\section{Conclusions}

We have shown that the manual and the automatic generated segmentation maps disagree. Even the two manual charts are inconsistent to some degree. However, the difference is mainly due to the analysts using the first-year ice classes differently. This supports the idea of sea ice charting being subjective. Manually drawn ice charts are commonly used for validation of automatic classification algorithms (Zakhvatkina et al., 2013; Kwon et al., 2013). This study has shown that the SoD charts should be used with care for validation purposes.

Our results suggests that utilizing polarimetric parameters in sea ice classification improves the classification accuracy. The $R K$ parameter, which has not previously been used for ice segmentation, distinguishes well between deformed and smooth ice and makes a valuable contribution to the segmentation.

Well aware that altering conditions (e.g. weather and viewing geometry) during image acquisition will change the backscattered signal, thus making image interpretation more complicated, we do not draw any conclusions relating mean value and standard deviation of each class and feature to an actual ice type. Some features may be invariant to changes in the viewing geometry (e.g. incidence angle), this needs to be further investigated in future studies.

The automatic algorithm separates the SAR scene into five unlabeled classes. The ice experts were able to distinguish three classes based on the optical images. Physical interpretation of the polarimetric parameters made it possible to distinguish the remaining unlabeled classes in terms of deformation level. The physical interpretation of the co-pol correlation angle and magnitude for medium and thick ice should be further investigated if they shall be used in class labeling. 
Table 3. Mean and standard deviation for the polarimetric features: co-pol ratio $\left(R_{\mathrm{HH} / \mathrm{VV}}\right.$ and $\left.R_{\mathrm{VV} / \mathrm{HH}}\right)$ given in $\mathrm{dB}$, co-pol correlation magnitude $(|\rho|)$ and co-pol correlation angle $(L \rho)$ given in degrees. The operators $\overline{(\cdot)}$ and $\sigma(\cdot)$ represents the mean and the standard deviation, respectively. AS-class is the unlabeled segments from the automated segmentation.

\begin{tabular}{lrrrrrrr}
\hline AS-class & $\bar{R}_{\mathrm{HH} / \mathrm{VV}}$ & $\overline{R_{\mathrm{VV} / \mathrm{HH}}}$ & $\sigma\left(R_{\mathrm{VV} / \mathrm{HH}}\right)$ & $\overline{|\rho|}$ & $\sigma(|\rho|)$ & $\overline{L \rho}$ & $\sigma(L \rho)$ \\
\hline 1 & 0.04 & 0.06 & 0.16 & 0.67 & 0.09 & 12.10 & 9.53 \\
2 & 0.40 & -0.34 & 0.13 & 0.73 & 0.05 & 7.29 & 5.93 \\
3 & -1.98 & 2.70 & 0.76 & 0.77 & 0.06 & 5.66 & 5.33 \\
4 & 0.08 & -0.01 & 0.13 & 0.77 & 0.05 & 2.28 & 4.47 \\
5 & 0.12 & -0.06 & 0.11 & 0.72 & 0.06 & 7.86 & 7.06 \\
\hline
\end{tabular}

The six features used as input to the algorithm should also be able to distinguish multiyear ice, but our scene did not contain any multiyear ice.

The number of classes is a critical input parameter which constrains the algorithm. If the number is too low, some segments will contain class mixtures. If the number is too high, the algorithm splits real ice classes, simply to attain the given number of classes. We found in our validation testing (Sect. 4.3) that the yellow class clearly is bimodal and should be split (see Fig. 8). This is in line with the interpretation of the ice experts (Table 2). This indicates that the constrained number of classes for the segmentation algorithm should be increased.

If the number of classes is increased by one, the algorithm will partition the data based on statistical criteria of optimality. This will not necessarily enforce the desired result, which is to split the bimodal class. Class boundaries may change and other classes may split, which is what we have experienced in our search for the seemingly optimal number of classes.

Polarimetric features are not expected to be invariant through seasonal changes. Thus the classes and the interpretation of the features acquired in one season are not directly transferable to scenes from other seasons. A possible solution is to use a priori information, such as knowledge of the ice history and ice charts from previous days to develop a so-called trained classifier.

Future work should focus on automatic and robust estimation of the number of classes, while noting that this is an inherently complicated problem, especially for highly detailed and heterogeneous sea ice scenes. For operational ice charting, automatic labeling will increase the efficiency compared to today's manual interpretation of SAR images. The labeling can be based on polarimetric parameters with a clear physical interpretation and statistical distribution models for these parameters.

Polarimetric SAR images makes it possible to segment and label ice classes based on physical properties. The polarimetric SAR data format is currently not suitable for operational ice charting, due to its limited swath width. However, the emerging compact polarimetry mode implemented on future sensors like PALSAR-2 and the Radarsat Constellation
Mission will combine pseudo-polarimetric information with wide coverage, which makes our work highly relevant (Charbonneau et al., 2010). Investigation of the extension of our method to compact polarimetry will be important for future work.

Acknowledgements. The authors acknowledge Vera Lund and Trond Robertsen of the Norwegian Ice Service for their analysis of sea ice stage of development and Thomas Kræmer at the University of Troms $\varnothing$ for advice in the geocoding process. We are grateful to the captain and crew onboard the Norwegian coast guard vessel Svalbard and the Airlift pilots and technicians onboard AS 350 and Dauphin for their assistance during the research cruise. This project was supported financially by the project "Sea Ice in the Arctic Ocean, Technology and Systems of Agreements" ("Polhavet", subproject "CASPER") of the Fram Centre, and by the Sentre for Ice, Climate and Ecosystems at the Norwegian Polar Institute. We are also funded by RDA Troms.

\section{References}

Bogdanov, A. V., Sandven, S., Johannessen, O. M., Alexandrov, V. Y., , and Bobylev, L. P.: Multisensor approach to automated classification of sea ice image data, IEEE T. Geosci. Remote, 43, 1648-663, 2005.

Breivik, L.-A., Eastwood, S., Karvonen, J., Dinessen, F., Fleming, A., Hamre, T., Pedersen, L. T., Saldo, R., and Buus-Hinkler, J.: Quality information document for OSI TAC sea ice products 011-001, -002, -003, -004, -006, -007, -009, -010, -011, -012, Technical report MYO2-OSI-QUID-011-ALL, version 1.3, Oslo, available at: http://catalogue.myocean.eu.org/static/resources/ myocean/quid/MYO2-OSI-QUID-011-ALL-V1.3.pdf, 2012.

Charbonneau, F., Brisco, B., R.K. Raney, H. M., Liu, C., Vachon, P., Shang, J., DeAbreu, R., Champagne, C., Merzouki, A., and Geldsetzer, T.: Compact polarimetry overiew and applications assessment, Can. J. Remote Sens. Suppl., 36, S298-S315, 2010.

Clausi, D. A. and Deng, H.: Operational segmentation and classification of SAR sea ice imagery, IEEE workshop on Advances in techniques for analysis of remotely sensed data, 268-275, 2004.

Clausi, D. A., Qin, A. K., Chowdhury, M. S., Yu, P., and Maillard, P.: MAGIC: MAp-Guided Ice Classification System, Can. J. Remote Sens. Suppl., 36, S13-S25, 2010. 
Deng, H. and Clausi, D. A.: Unsupervised segmentation of synthetic apterture radar sea ice imagery using a novel markov random field model, IEEE T. Geosci. Remote, 43, 528-538, 2005.

Dierking, W., Skriver, H., and Gudmandsen, P.: SAR polarimetry for sea ice classification, in: Proc. POLinSAR 2003 - Workshop on Applications of SAR Polarimetry and Polarimetric Interferometry, vol. ESA SP-529, 109-118, Frascati, Italy, 2003.

Doulgeris, A. P.: A simple and extendable segmentation method for multi-polarisation SAR images, in: Proc. POLinSAR 2013 - 6th Int. Workshop on Science and Applications of SAR Polarimetry and Polarimetric Interferometry, vol. ESA SP-713, 8 pp., Frascati, Italy, in press, 2013.

Doulgeris, A. P. and Eltoft, T.: Scale Mixture of Gaussian modelling of polarimetric SAR data, EURASIP J. Adv. Signal Process., 2010, 1-12, doi:10.1155/2010/874592, 2010.

Drinkwater, M. R., Kwok, R., Rignot, E., Israelsson, H., Onstott, R. G., and Winebrenner, D. P.: Potential Applications of Polarimetry to the Classification of Sea Ice, in: Microwave remote sensing of sea ice, edited by: Carsey, F. D., no. 68 in Geophysical Monograph, 419-430, AGU, 1992.

Geldsetzer, T. and Yackel, J. J.: Sea ice type and open water discrimination using dual co-polarized C-band SAR, Can. J. Remote Sens., 35, 73-84, 2009.

Gill, J. and Yackel, J.: Evaluation of C-band SAR polarimetric parameters for discriminating of first-year sea ice types, Can. J. Remote Sens., 38, 306-323, 2012.

Haas, C., Lobach, J., Hendricks, S., Rabenstein, L., and Pfaffling, A.: Helicopterborne measurements of sea ice thickness, using a small and lightweight, digital em system, J. Appl. Geophys., 67, 234-241, 2009.

Hara, Y., Atkins, R. G., Shin, R. T., Kong, J. A., Yueh, S. H., and Kwok, R.: Application of neural networks for sea ice classification in polarimetric SAR images, IEEE Trans. Geosci. Remote Sens., 33, 740-748, 1995.

Hartigan, J. A.: Clustering Algorithms, Wiley, New York, 1975.

Karvonen, J.: C-band sea ice SAR classification based on segmentwise edge features, in: Geoscience and remote sensing new achievements, edited by: imperatore, P. and Riccio, D., InTech, available at: http://www.intechopen.com/books/geoscience-andremotesensing-new-achievements/, 2010.

Karvonen, J. A.: Baltic sea ice SAR segmentation and classification using modified pulse-coupled neural networks, IEEE T. Geosci. Remote, 42, 1566-1574, 2004.

Kwok, R., Rignot, E., and Holt, B.: Identification of sea ice types in spaceborne Synthetic Aperture Radar data, J. Geophys. Res., 97, 2391-2402, 1992.

Kwok, R., Cunningham, G. F., Wensnahan, M., Rigor, I., Zwally, H. J., and Yi, D.: Thinning and volume loss of the Arctic Ocean sea ice cover: 2003-2008, J. Geophys. Res., 114, C07005, doi:10.1029/2009JC005312, 2009.

Kwon, T.-J., Li, J., and Wong, A.: ETVOS: An enhanced total variation optimization segmentation approach for SAR sea-ice image segmentation, IEEE T. Geosci. Remote, 51, 925-934, 2013.
Lee, J.-S. and Pottier, E.: Polarimetric Radar Imaging, from basics to applications, Taylor \& Francis Group, 2009.

MANICE: Manual of Standard Procedures for Observing and Reporting Ice Conditions, Canadian Ice Service, ISBN: 0-66062858-9, 2005.

Maslanik, J., Stroeve, J., Fowler, C., and Emery, W.: Distribution and trends in Arctic sea ice age through spring 2011, Geophys. Res. Lett., 38, L13502, doi:10.1029/2011GL047735, 2011.

Mundy, C. J. and Barber, D. A.: On the relationship between spatial patterns of sea-ice type and the mechanisms which create and maintain the North Water (NOW) polynya, Atmos. Ocean, 39, 327-341, 2001.

Ochilov, S. and Clausi, D.: Automated classification of operational SAR sea ice images, in: Proc. Canadian Conference Computer and Robot Vision, 40-45, 2010.

Oliver, C. and Quegan, S.: Understanding Syntheric Aperture Radar Images, SciTech Publishing, ISBN:1-891121-31-6, 2004.

Onstott, R. G. and Shuchman, R. A.: Synthetic Aperture Radar Marine User's manual, in: SAR measurements of sea ice, edited by: Jackson, C. and Apel, J. R., NOAA, 81-115, 2004.

Renner, A. H. H., Hendricks, S., Gerland, S., Beckers, J., Haas, C., and Krumpen, T.: Large-scale ice thickness distribution of first-year sea ice in spring and summer north of Svalbard, Ann. Glaciol., 54, 13-18, 2013.

Samadani, R.: a finite mixtures algorithm for finding proportions in SAR images, IEEE T. Image Process., 4, 1182-1186, 1995.

Scheuchl, B., Caves, R., Cumming, I., and Staples, G.: Automated sea ice classification using spaceborne polarimetric SAR data, in: Proc. IGARSS 2001, 3117-3119, 2001.

Scheuchl, B., Hajnsek, I., and Cumming, I.: Sea ice classification using multi-frequency polarimetric SAR data, IGARSS, 3, $1914-$ 1916, 2002.

Scheuchl, B., Hajnsek, I., and Cumming, I.: Classification strategies for polarimetric SAR sea ice data, in: Proc. POLinSAR 2003 Workshop on Applications of SAR Polarimetry and Polarimetric Interferometry, vol. ESA SP-529, 57.1-57.6, Frascati, Italy, 2003.

Thomsen, B., Nghiem, S., and Kwok, R.: Polarimetric C-band SAR observations of sea ice in the Greenland Sea, in: Proc. IGARSS 1998, 2502-2504, 1998a.

Thomsen, B., Pedersen, L., Skriver, H., and Dierking, W.: Polarimetric EMISAR observations of sea ice in the Greenland Sea, in: Future Trends in Remote Sensing, edited by: Gudmandsen, P., Taylor \& Francis, 345-351, 1998b.

World Meteorological Organization: Sea-Ice Nomenclature, Geneva, Switzerland, 1989.

Yu, Q. and Clausi, D. A.: IRGS: Image segmentation using edge penalties and region growing, IEEE Trans. Pattern analysis and machine intelligence, 30, 2126-2139, 2008.

Zakhvatkina, N., Alexandrov, V., Johannessen, O., Sandven, S., and Frolov, I.: Classification of sea ice types in ENVISAT synthetic aperture radar images., IEEE T. Geosci. Remote, 51, 2587-2600, 2013. 